\title{
Effect of heat treatment temperature on microstructure and electrochemical properties of hollow carbon spheres prepared in high-pressure argon
}

\author{
BOYANG LIU*, YUN ZHOU, DECHANG JIA ${ }^{1}$, PENGJIAN ZUO ${ }^{2}$, YINGFENG SHAO ${ }^{2}$ \\ and JINGWEI ZHANG \\ Institute of Marine Materials Science and Engineering, Shanghai Maritime University, Shanghai 201306, China \\ ${ }^{1}$ Institute for Advanced Ceramics, ${ }^{2}$ Department of Applied Chemistry, Harbin Institute of Technology, \\ Harbin 150001, China \\ ${ }^{3}$ Logistics Engineering College, Shanghai Maritime University, Shanghai 201306, China
}

MS received 30 May 2008; revised 13 March 2011

\begin{abstract}
Heat treatment was carried out between 800 and $1200^{\circ} \mathrm{C}$ to investigate its effects on the microstructure and electrochemical properties of the hollow carbon spheres (HCSs) prepared in high-pressure argon. Samples were characterized by X-ray diffraction, Raman spectroscopy, field-emission scanning electron microscopy, high-resolution transmission electron microscopy and $\mathbf{N}_{2}$ adsorption-desorption isotherms. The graphitization of the HCSs was improved with increase of heat treatment temperature. Mesopores of $c a$. $4 \mathrm{~nm}$ in diameter were created on the HCSs after the heat treatment. The results of electrochemical performance measurements for the HCSs as anode material for lithium ion batteries indicate that the discharge capacity of the HCSs is improved after heat treatment at $800^{\circ} \mathrm{C}$ compared with the as-prepared HCSs and have a maximum value of $357 \mathrm{mAh} / \mathrm{g}$ and still retains $303 \mathrm{mAh} / \mathrm{g}$ after 40 cycles. However, the discharge capacity of the HCSs decreases and the cycling performance is improved with the increase of heat treatment temperature.
\end{abstract}

Keywords. Hollow carbon spheres; heat treatment; gas pressure; lithium ion battery.

\section{Introduction}

The development of portable devices in recent years has underlined the need for small and efficient lithium ion batteries. In fact, lithium metal is the most attractive anode material in rechargeable batteries because of its large negative electrode potential and high specific capacity. However, the lithium electrode has serious problems because it does not have long enough cycling life and may have safety problems caused by dendrites growing upon cycling (Tatsumi et al 1995).

As alternative anode materials, carbonaceous materials are extensively used in lithium ion batteries owing to their low cost, suitable working potential, long cycling life, high cycle efficiency and safety (Tirado et al 2007). Therefore, various carbon types including natural and synthetic graphite, carbon nanotubes, amorphous carbon, cokes and mesocarbon microbeads (MCMB), etc. have been investigated as electrode material candidates in lithium ion batteries (Nishizawa et al 1998; Shi 1998; Schoonman 2000; Yang and $\mathrm{Wu}$ 2001). However, the high irreversible capacity loss in the first cycle and poor

\footnotetext{
*Author for correspondence (boyang.liu@yahoo.com.cn)
}

high rate charge-discharge performance, which involves electrolyte decomposition and solid electrolyte interface (SEI) film formation, are still the problems in carbonaceous anode materials (Zhang et al 2001). Fortunately, studies show that the particle size, surface area, electrode thickness and porosity can have a significant influence on the electrochemical performance of anode materials (Zaghiba et al 2001), thus leading to the controlled preparation of new carbon materials with different structures and forms for practical needs in lithium ion batteries.

Hollow carbon spheres (HCSs), which are attractive as anode materials, have a good rate performance because the hollow structure facilitates the transport of lithium ions by offering a shorter solid-state diffusion length (Lee et al 2005). Additionally, they can serve as protectors and provide void spaces for other anode materials (such as Sn) suffering from great volume change and aggregation problems in lithium insertion and extraction reactions (Lee et al 2003). In recent years, numerous efforts have been devoted to the exploration of various synthesis approaches for HCSs with emphasis on solvothermal and template assisted method (Liu et al 2003; Su et al 2006). However, the low yield and complexity of the process are still the main factors that hinder the applications of HCSs. 
In our previous paper (Liu et al 2007), a convenient and efficient method has been suggested for preparation of HCSs with several micrometers in diameter using ferrocene and ammonium chloride as reactants in highpressure argon. Moreover, the yield of HCSs is also considerably high, which is suitable for large scale synthesis. The heat treatment process, which will influence the crystalline form of carbon materials, was then carried out at $800-1200^{\circ} \mathrm{C}$ in present paper to investigate its effects on the microstructure of the HCSs and electrochemical properties in lithium ion batteries. The results should be a valuable addition to the research of HCSs as anode materials in lithium ion batteries, which may be available in commercial applications.

\section{Experimental}

Details of the method for preparation of HCSs have been discussed elsewhere (Liu et al 2007). Briefly, $40 \mathrm{~g}$ of ferrocene and $24 \mathrm{~g}$ of ammonium chloride were mixed and put into a graphite crucible. The crucible was placed in a gas pressure furnace, which was then filled with $\mathrm{Ar}$ up to $2 \mathrm{MPa}$ after being pumped to $0 \cdot 1 \mathrm{~Pa}$. Then, the crucible was heated up to $600^{\circ} \mathrm{C}$ at a ramp rate of $20^{\circ} \mathrm{C} / \mathrm{min}$. After being held for $5 \mathrm{~min}$, the furnace was cooled down naturally. The as-prepared product was thoroughly washed with $36 \% \mathrm{HCl}$ solution and deionized water for several times in sequence, and finally dried at $100^{\circ} \mathrm{C}$ for $12 \mathrm{~h}$. The HCSs after washing were heat-treated with flow $\mathrm{Ar}$ in a tube furnace for an hour at 800, 1000 and $1200^{\circ} \mathrm{C}$, separately.

The product was characterized by Shimadzu xrd-6000 $\mathrm{X}$-ray diffractometry (XRD) with $\mathrm{CuK} \alpha$ radiation $(\lambda=1.5418 \AA)$. The morphologies of the product were recorded by Hitachi S-4700 field emission scanning electron microscopy (SEM) and Phillips Tecnai F30 transmission electron microscopy (TEM). The Raman measurement was carried out with a Jobin Yvon Lab Ram Raman microscope at an excitation laser wavelength of $632.8 \mathrm{~nm}$. The $\mathrm{N}_{2}$ adsorption-desorption isotherm was determined on a Quantochrome Autosorb-1-C instrument at $77.4 \mathrm{~K}$ with a sample outgassed for $5 \mathrm{~h}$ at $200^{\circ} \mathrm{C}$. Specific surface area (SBET) was calculated on the basis of the BET theory.

The electrodes were prepared by drying an electrode slurry (80\% active material, $5 \%$ acetylene black and $15 \%$ PVDF dissolved in $\mathrm{N}$-methyl-2-pyrrolidine) on a copper foil at $120^{\circ} \mathrm{C}$ for $14 \mathrm{~h}$ under vacuum. Two-electrode halfcells were assembled in a glove box filled with argon using a lithium foil as a counter electrode, the Celgard 2400 as separator, and $1 \mathrm{M} \mathrm{LiPF}_{6}$ in a $1: 1: 1(\mathrm{v} / \mathrm{v} / \mathrm{v}) \mathrm{mix}-$ ture of ethylene carbonate (EC), diethyl carbonate (DEC) and dimethyl carbonate (DMC) as the electrolyte. The charge-discharge measurements of cells were carried out using a programmable battery test system (BTS, Shenzhen,
China). The cells were discharged and charged between 0.01 and $1.5 \mathrm{~V}$ vs $\mathrm{Li} / \mathrm{Li}^{+}$at a constant current density of $0 \cdot 15 \mathrm{~mA} / \mathrm{cm}^{2}$. The cyclic voltammograms were recorded on a CHI 630A electrochemical workstation.

\section{Results and discussion}

The SEM images of the HCSs treated at different temperatures are shown in figure 1 . It is obvious that most of the products exhibit perfect spherical morphology. The spheres vary from 1 to $5 \mu \mathrm{m}$ in diameter and have hollow structure improved by the morphology of the ruptured ones. Details of the structures of the HCSs prepared by this method have been discussed elsewhere (Liu et al 2007). However, their morphologies are independent on the heat treatment temperature and the surfaces of the spheres are very smooth.

Figure 2a shows the XRD pattern of the as-prepared HCSs and the only evident broad peak around $2 \theta=26^{\circ}$ should correspond to the 002 planes of graphite, suggesting the graphitization of the HCSs is poor because of the low synthesis temperature. After the heat treatment at $800^{\circ} \mathrm{C}$, the 101 diffraction peak of graphite at $2 \theta=44^{\circ}$ appears, as shown in figure $2 \mathrm{~b}$, which indicates that the graphitization is improved. The XRD patterns do not have significant difference when the heat treatment temperature was further raised. However, for all the XRD patterns, the position of 002 diffraction peak tends to move to $26^{\circ}$ with the increase of heat treatment temperature. Consequently, the interplanar distance of 002 planes is reduced by the heat treatment, which means that the graphitization of the HCSs is improved.

In order to further investigate the microstructure of the HCSs, Raman spectra were recorded at room temperature, as shown in figure 3 . The prominent peaks at 1330 and $1583 \mathrm{~cm}^{-1}$ in all the curves correspond to the carbon D- and G-band vibration mode, respectively. The G-peak originates from the vibrations of $s p^{2}$-bonded carbon atoms in a two-dimensional graphite plane, while the Dpeak is related to double-resonance Raman process in disordered carbon (Antunes et al 2006). The intensity of G-band is not evidently improved with the increase of temperature, suggesting the graphitization of the HCSs is poor even after the heat treatment. Although the graphene sheets tend to swing into more or less parallel positions according to the XRD results, the turbostratic misalignment could not be relieved at low temperature. Therefore, the HCSs prepared by this method could be regarded as a kind of hard carbon, which can not be transformed into crystalline graphite. This can also be proved by the highresolution TEM morphologies of the HCSs treated at different temperatures, as shown in figure 4 . The images show both the fine structure of the shell near the surface of HCSs, and the disordered atomic arrangement rather than well-ordered structure corresponding to crystallized graphite is observed. 

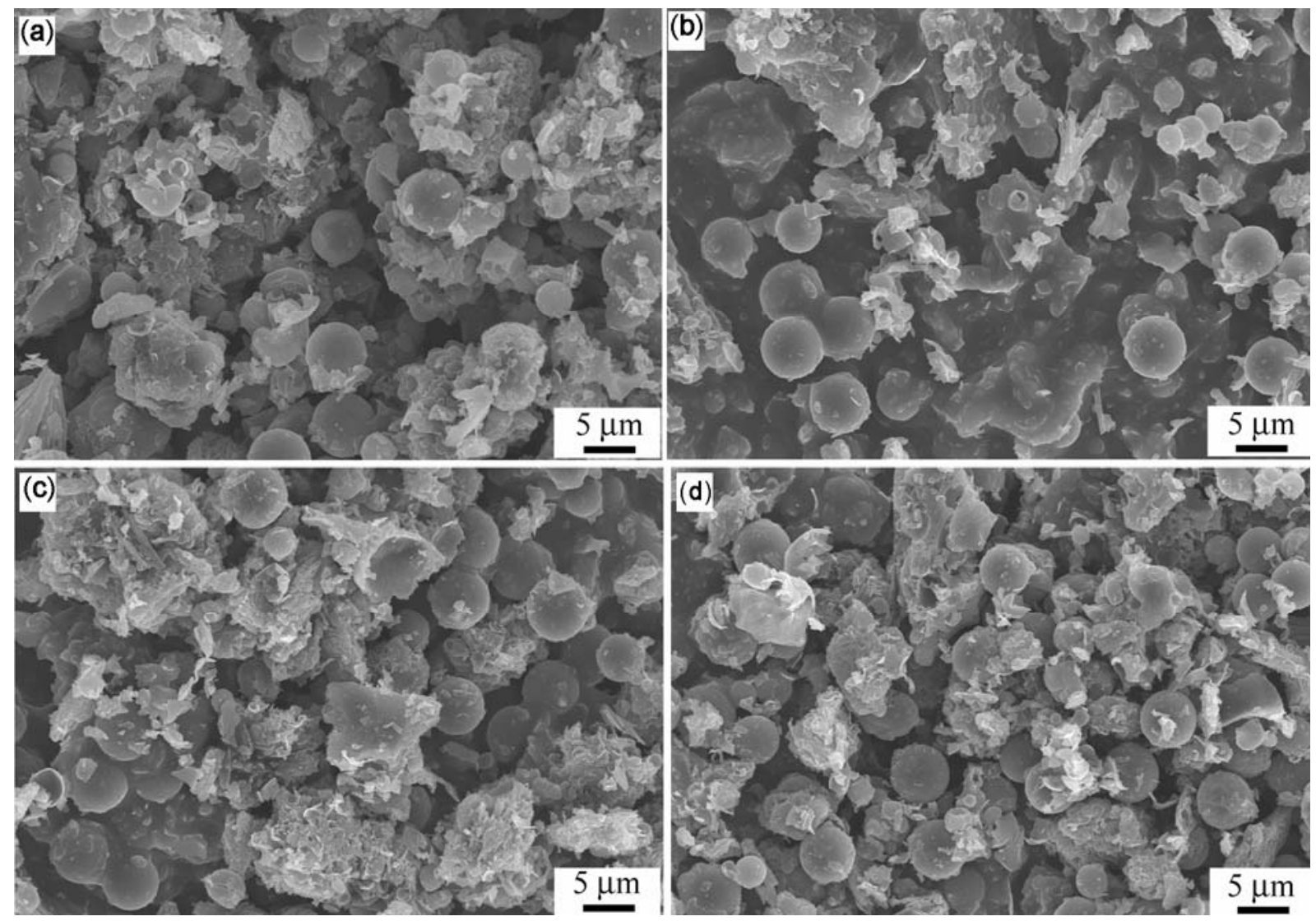

Figure 1. SEM images of the HCSs treated at different temperatures: (a) as-prepared; (b) $800^{\circ} \mathrm{C} ;(\mathbf{c}) 1000^{\circ} \mathrm{C}$ and (d) $1200^{\circ} \mathrm{C}$.

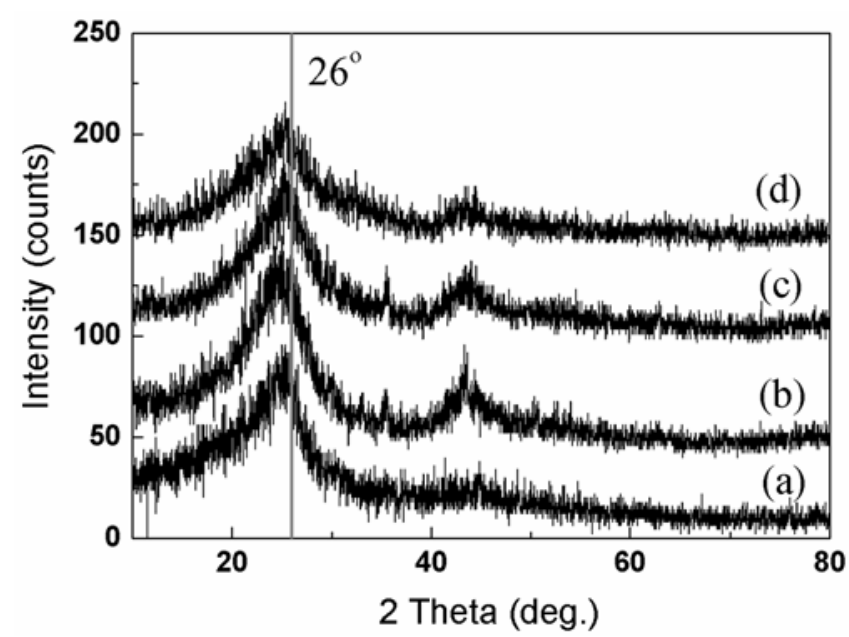

Figure 2. XRD patterns of the HCSs treated at different temperatures: (a) as-prepared; (b) $800^{\circ} \mathrm{C}$; (c) $1000^{\circ} \mathrm{C}$ and (d) $1200^{\circ} \mathrm{C}$.

The $\mathrm{N}_{2}$ adsorption-desorption isotherms were recorded in order to understand the effects of temperature on the pore structure of the HCSs. Figure 5a shows that the as-prepared HCSs exhibit type IV isotherm classification with an H3 hysteresis loop. The hysteresis in the whole

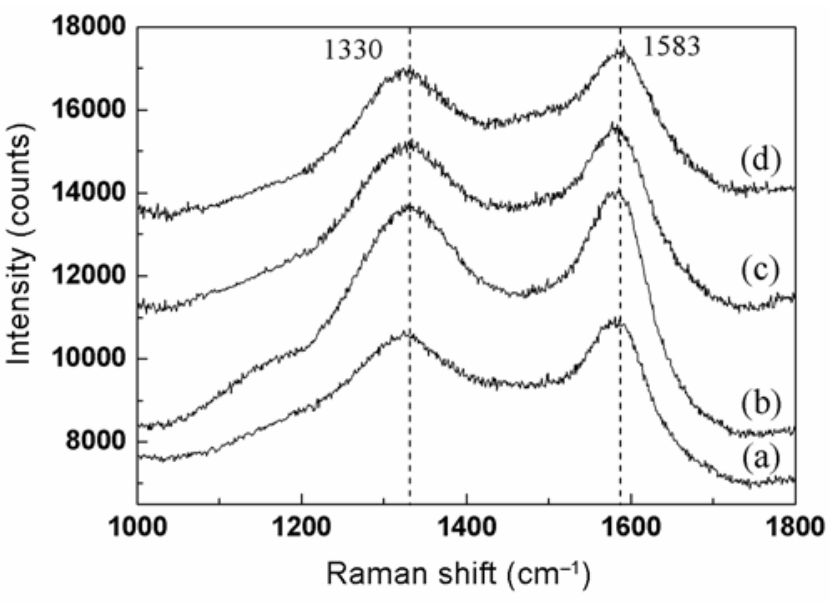

Figure 3. Raman spectra of the $\mathrm{HCSs}$ treated at different temperatures: (a) as-prepared; (b) $800^{\circ} \mathrm{C}$; (c) $1000^{\circ} \mathrm{C}$ and (d) $1200^{\circ} \mathrm{C}$.

range of pressure suggests the wide distribution of pores in the HCSs. However, after the heat treatment at 800, 1000 and $1200^{\circ} \mathrm{C}$, the hysteresis loops tend to close around $P / P_{0}=0 \cdot 5$, indicating the existence of mesopores. The pore size distribution of HCSs treated at different 

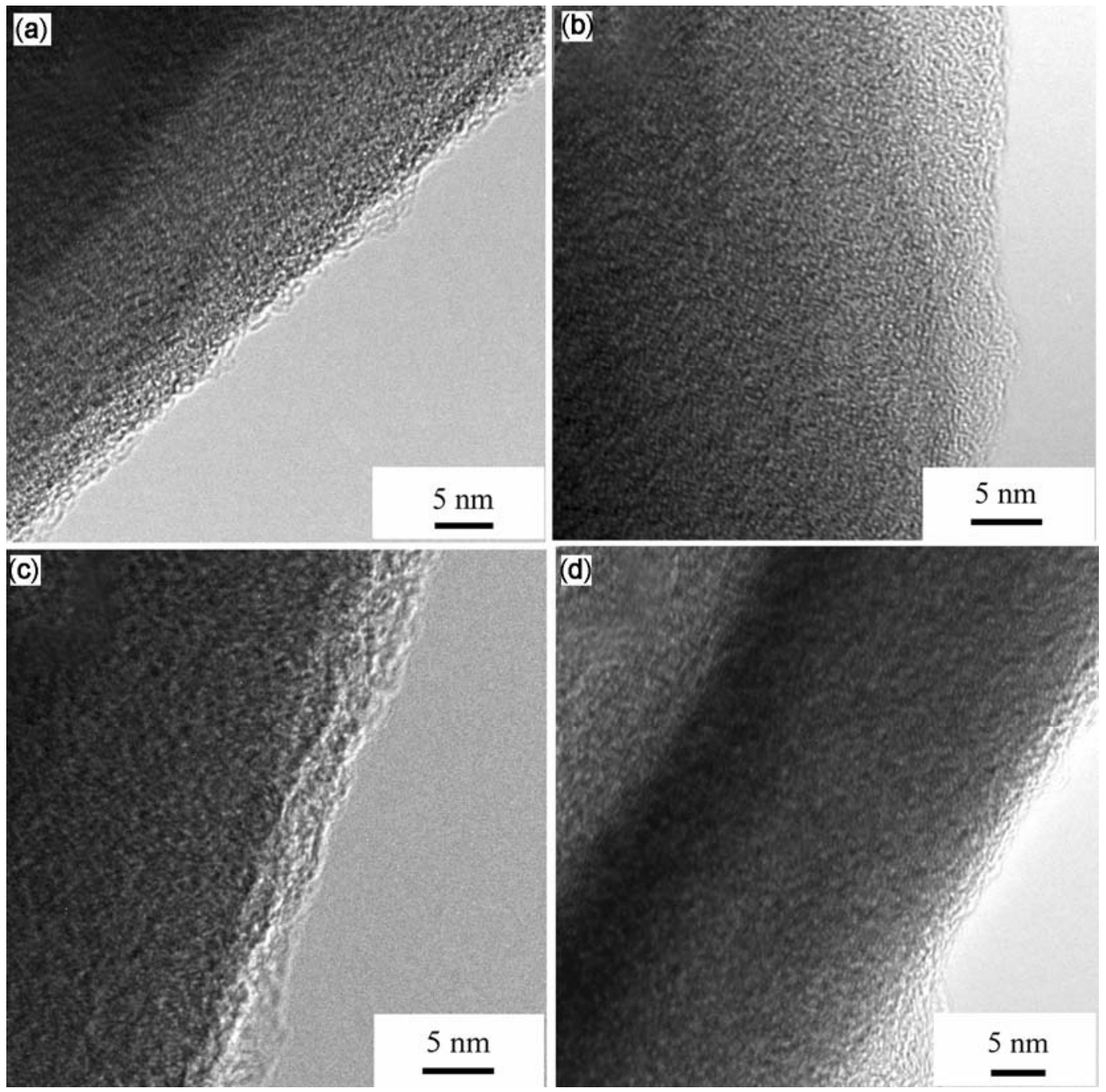

Figure 4. HRTEM images of the HCSs treated at different temperatures: (a) as-prepared; (b) $800^{\circ} \mathrm{C}$; (c) $1000^{\circ} \mathrm{C}$ and (d) $1200^{\circ} \mathrm{C}$.
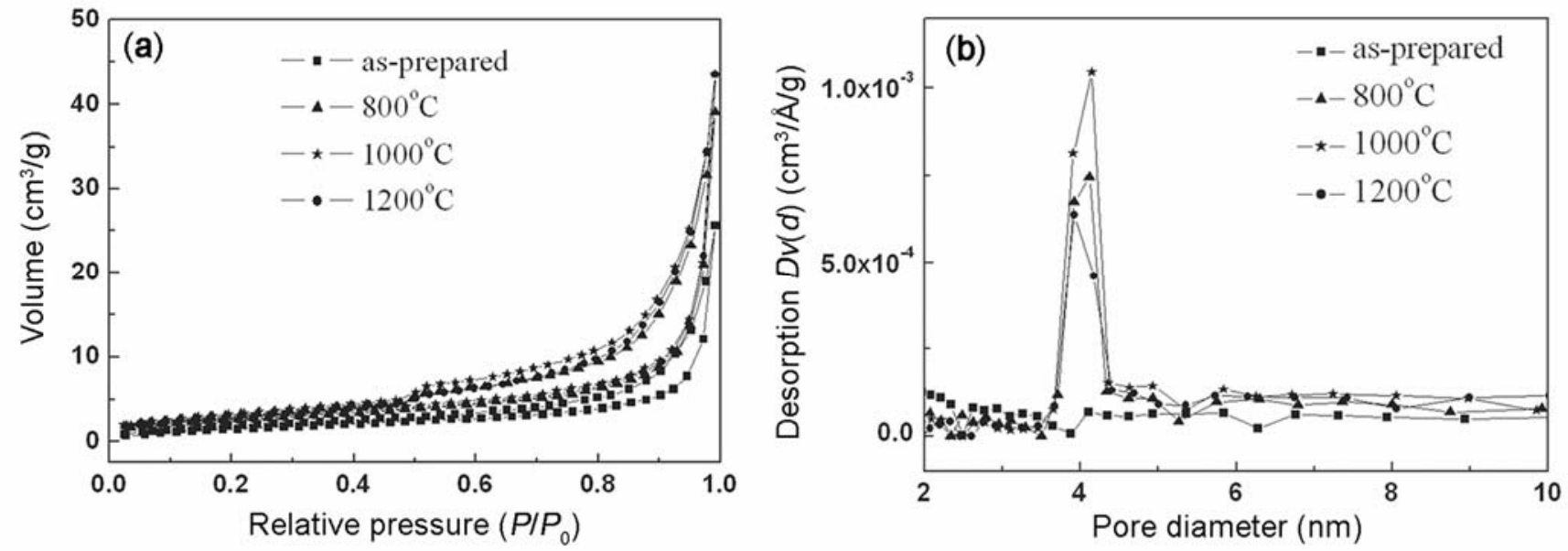

Figure 5. (a) Nitrogen adsorption-desorption isotherms and (b) the pore size distribution of the HCSs treated at different temperatures. 

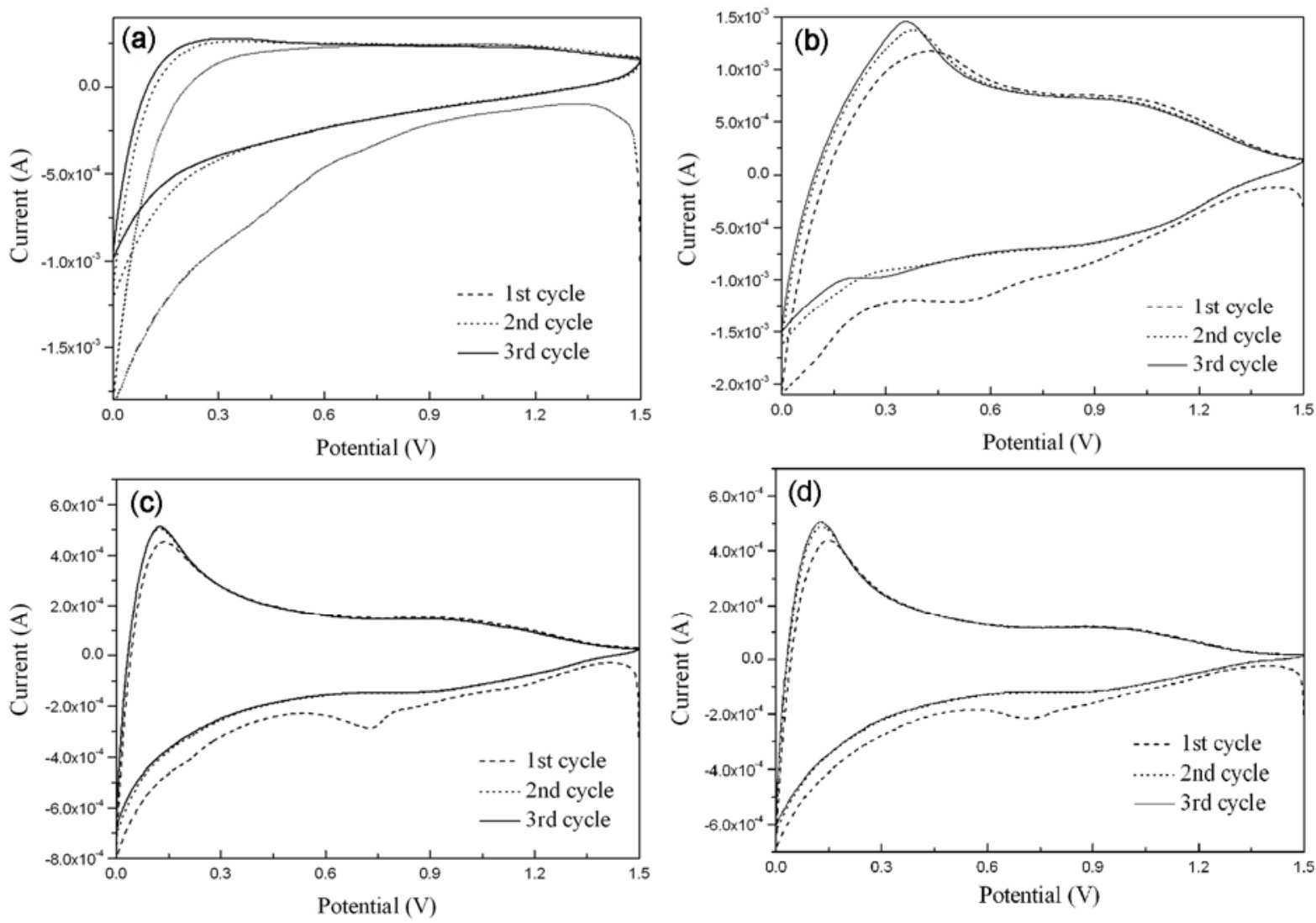

Figure 6. Cyclic voltammograms of HCSs treatment at different temperatures: (a) as-prepared; $(\mathbf{b}) 800^{\circ} \mathrm{C}$; (c) $1000^{\circ} \mathrm{C}$ and (d) $1200^{\circ} \mathrm{C}$.

Table 1. SBET of the HCSs-treated at different temperatures.

Heat treatment temperature $\left({ }^{\circ} \mathrm{C}\right) \quad$ None $\quad 800 \quad 1000 \quad 1200$ $\begin{array}{lllll}\operatorname{SBET}\left(\mathrm{m}^{2} / \mathrm{g}\right) & 5.75 & 9.28 & 9.96 & 9.24\end{array}$

temperatures has a maximum at $4 \mathrm{~nm}$ and is independent on the temperature, as shown in figure $5 \mathrm{~b}$. However, the pore size of the as-prepared HCSs does not show a concentrated distribution. Additionally, the SBET of the HCSs, increasing with the heat treatment temperature up to $1000^{\circ} \mathrm{C}$, is low, which may be a result of the large diameter of the HCSs, as shown in table 1. The asprepared HCSs of low graphitization may have lots of defect sites that can be oxidized by exposing to the air or during the acid washing process, forming carboxyl groups, hydroxyl groups and carbonyl groups, etc. (Suh and Shim 1997). The functional groups will be removed at high temperature, leading to the formation of new mesopores with a uniform size. Thus, the pores have a concentrated size distribution after the heat treatment and the SBET will increase with temperature compared with the as-prepared HCSs. However, when the temperature is $1200^{\circ} \mathrm{C}$, the heat treatment is also helpful for the graphitization of HCSs and the SBET tends to decrease.
Figure 6a shows the cyclic voltammograms of the as-prepared HCSs and there is no obvious peak, which is similar to the pyrolysis carbon as reported in Suh's work (Suh et al 1999). This should be caused by the poor graphitization of HCSs (Zhang et al 2006). After the heat treatment at $800^{\circ} \mathrm{C}$, the oxidation peak at about $0.4 \mathrm{~V}$ corresponding to the deinsertion of lithium ion from HCSs becomes evident, suggesting that the graphitization of HCSs is improved, as shown in figure 6b. After heat treatment at 1000 and $1200^{\circ} \mathrm{C}$, the potential of the oxidation peak is reduced to $0 \cdot 15 \mathrm{~V}$, suggesting the hysteresis effect of deinsertion of lithium from HCSs is decreased. On the other hand, the reduction peak at about $0.7 \mathrm{~V}$, which exists only on the first cycle and disappeared on the subsequent cycles, corresponds to the formation of SEI film owing to the decomposition of electrolyte, as shown in figures $6 \mathrm{c}$ and d. On the basis of previous work, the SEI film for graphite anode typically forms at $0.7 \mathrm{~V}$ (Wang and Yoshio 2001). Consequently, according to figure 6 , it is concluded that the graphitization of HCSs is indeed improved at high temperature, which is consistent with the XRD results.

The electrochemical properties of the HCSs as anode materials for lithium ion batteries were investigated by discharge-charge measurement and the results are shown in figure 7. During the first insertion process, the 

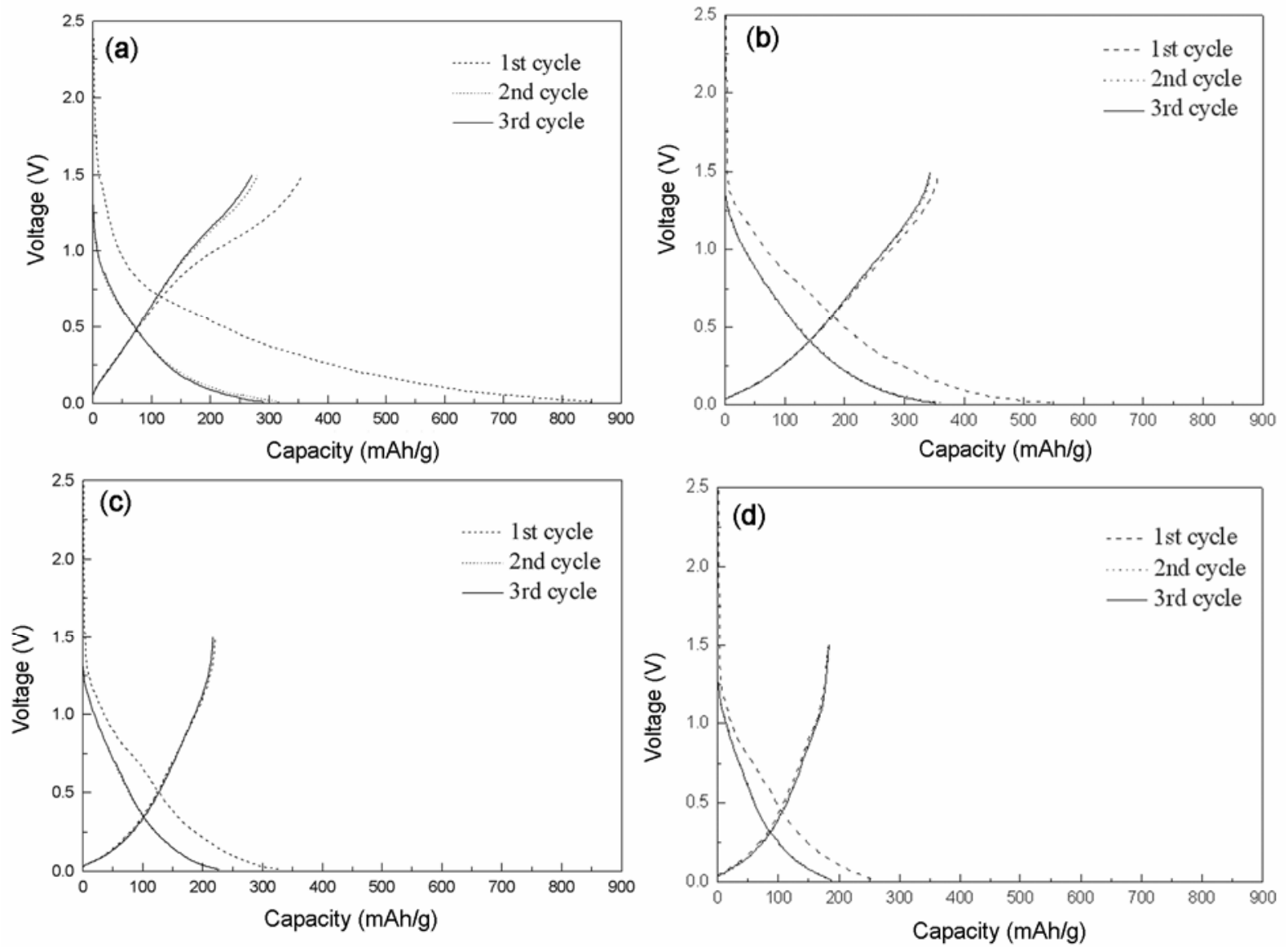

Figure 7. Charge-discharge curves of the HCSs treated at different temperatures: (a) as-prepared; (b) $800^{\circ} \mathrm{C}$; (c) $1000^{\circ} \mathrm{C}$ and (d) $1200^{\circ} \mathrm{C}$.

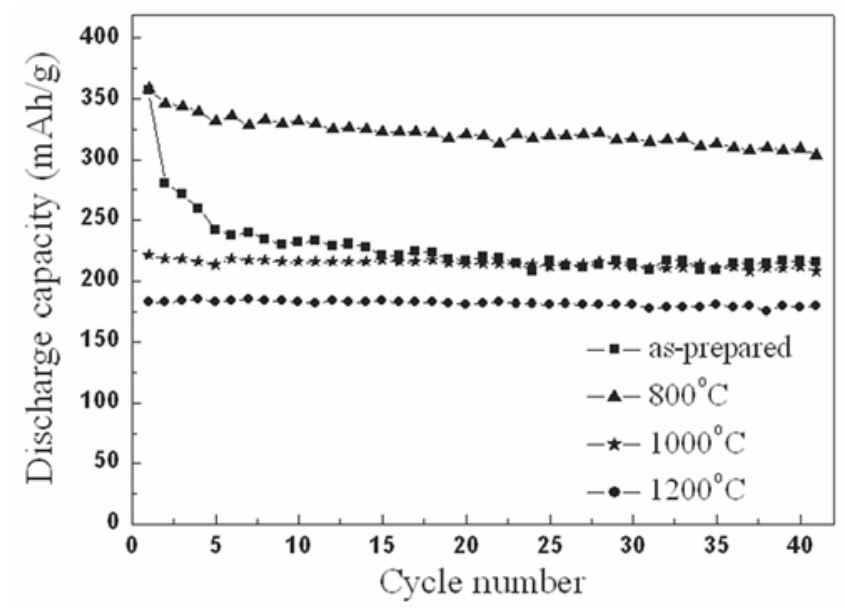

Figure 8. Cyclic discharge capacity for the HCSs electrodes treated at different temperatures: (a) as-prepared; (b) $800^{\circ} \mathrm{C}$; (c) $1000^{\circ} \mathrm{C}$ and (d) $1200^{\circ} \mathrm{C}$.

as-prepared HCSs exhibit a large irreversible capacity, corresponding to a Coulomb efficiency of about $42 \%$, as shown in figure $7 \mathrm{a}$. This low Coulomb efficiency is gene- rally related to the SEI film formation and the organic groups remaining in the carbons. After the heat treatment at $800^{\circ} \mathrm{C}$, the irreversible capacity of the HCSs is greatly reduced because of the elimination of the organic groups while the reversible capacity after the first cycle is enhanced compared with the as-prepared HCSs. However, the reversible capacity of HCSs declines with the increase of the heat treatment temperature, as shown in figures $7 \mathrm{c}$ and $\mathrm{d}$. The small slopes at about $0.7 \mathrm{~V}$ correspond to the formation of SEI film on the surface of HCSs, which is in agreement with the cyclic voltammograms in figure 6 . From these curves, there is no distinct platform, which usually appears in graphite, and the lithium insertion voltage of the HCSs treat at different temperatures is much higher than that of graphite. This high potential gradient and high average voltage will result in a much stronger driving force for lithium migration during the lithium insertion reaction compared with the flattened and low insertion potential in graphite. Therefore the sloping voltage of HCSs is more favourable for the rapid charge-discharge during high-rate cell operation (Atlung et al 1984). 


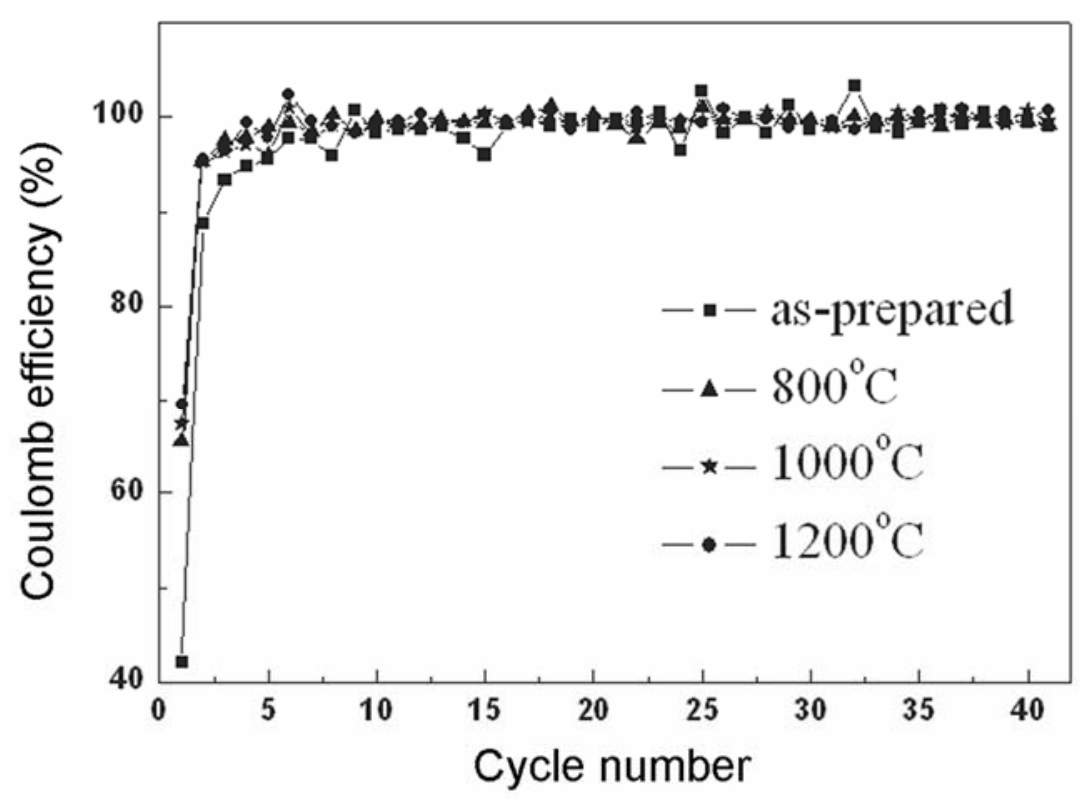

Figure 9. Coulomb efficiency for the HCSs electrodes treated at different temperatures: (a) as-prepared; (b) $800^{\circ} \mathrm{C}$; (c) $1000^{\circ} \mathrm{C}$ and (d) $1200^{\circ} \mathrm{C}$.

Figure 8 shows the curves of discharge capacity vs cycle number for the HCSs electrodes in lithium ion batteries. The discharge capacity of the as-prepared HCSs shows an initial reversible capacity of $357 \mathrm{mAh} / \mathrm{g}$, and then decreases largely up to the 5th cycle and gradually after this cycle with increasing cycle number. The electrodes still maintain a capacity of $215 \mathrm{mAh} / \mathrm{g}$ after 40 cycles with about $1 \%$ loss per cycle. After the heat treatment at $800^{\circ} \mathrm{C}$, it is worthwhile to note that the cycling performance was greatly improved and the capacity of HCSs still remained $303 \mathrm{mAh} / \mathrm{g}$ at the 40th cycle. This may be caused by the partial graphitization of the HCSs depending on the heat treatment, which is helpful for improving the microstructure of HCSs for lithium ion insertion. However, when the heat treatment temperature was further raised to 1000 and $1200^{\circ} \mathrm{C}$, the discharge capacity of the HCSs is greatly reduced to 221 and $182 \mathrm{mAh} / \mathrm{g}$, respectively, although the cycling performance is further improved. This result is consistent with Dahn's work that the capacity of carbon materials usually decreases with the heat treatment temperature below $1500^{\circ} \mathrm{C}$ (Dahn et al 1995). Moreover, the Coulomb efficiencies of the HCSs electrodes become constant to be nearly $100 \%$ after the several cycles in spite of the low initial efficiencies, as shown in figure 9. The first Coulomb efficiency increases with the heat treatment temperature and reaches $67 \%$ for the HCSs treated at $1200^{\circ} \mathrm{C}$ compared with $42 \%$ for the as-prepared HCSs. Thus, it can be concluded from the above results that the HCSs after the heat treatment at $800^{\circ} \mathrm{C}$ is a promising anode material for lithium ion batteries, whereas the first Coulomb efficiency should be further elevated.

\section{Conclusions}

The graphitization of the HCSs with several micrometers in diameter, prepared via the reaction between ferrocene and ammonium chloride in high pressure argon, is poor and can be partially improved by the heat treatment conducted at $800-1200^{\circ} \mathrm{C}$. The SBET of the HCSs is enhanced after the heat treatment and mesopores of $c a$. $4 \mathrm{~nm}$ in diameter are created by the elimination of organic groups. The $\mathrm{HCSs}$ heat treated at $800^{\circ} \mathrm{C}$ have a maximum discharge capacity of $357 \mathrm{mAh} / \mathrm{g}$ and still retain $303 \mathrm{mAh} / \mathrm{g}$ after 40 cycles, but the discharge capacity of HCSs after the heat treatment decreases with the increase of temperature. Although the first-cycle Coulomb efficiency still needs to be improved for practical application, the HCSs may be a promising anode material for lithium ion batteries in future.

\section{Acknowledgements}

This work is supported by National Natural Science Foundation of China (No. 51002094), Natural Science Foundation of Shanghai (No. 10ZR1413400), 'Chen Guang' project of Shanghai Municipal Education Commission and Shanghai Education Development Foundation Science and Technology (No. 09CG53), Science and Technology Innovation Program of Shanghai (11dz1206002).

\section{References}

Antunes E F, Lobo A O, Corat E J, Trava-Airoldi V J, Martin A A and Veríssimo C 2006 Carbon 442202 
Atlung S, Zachau-Christiansen B, West K and Jacobsen T 1984 J. Electrochem. Soc. 1311200

Dahn J R, Zheng T, Liu Y H and Xue J S 1995 Science 270590

Lee K T, Jung Y S and Oh S M 2003 J. Am. Chem. Soc. 125 5652

Lee K T, Lytle J C, Ergang N S, Oh S M and Stein A 2005 Adv. Funct. Mater. 15547

Liu B Y, Jia D C, Meng Q C and Rao J C 2007 Carbon 45668

Liu J W, Shao M W, Tang Q, Chen X Y, Liu Z P and Qian Y T 2003 Carbon 411682

Nishizawa M, Hashitani R, Itoh T, Matsue T and Uchida I 1998 Electrochem. Solid S. 110

Schoonman J 2000 Solid State Ionics 1355

Shi H 1998 J. Power Sources $\mathbf{7 5} 64$

Su F B, Zhao X S, Wang Y, Wang L K and Lee J Y 2006 J. Mater. Chem. 164413
Suh M C and Shim S C 1997 Chem. Mater. 9192

Suh M C, Jung Y, Kwak J and Shim S C 1999 Synthetic Met. 100195

Tatsumi K, Iwashita N, Sakaebe H, Shioyama H and Higuchi S 1995 J. Electrochem. Soc. 142716

Tirado J L, Santamaría R, Ortiz G F, Menéndez R, Lavela P, Jiménez-Mateos J M, Gómez García F J and Concheso A 2007 Carbon 451396

Wang H Y and Yoshio M 2001 J. Power Sources 93123

Yang Z H and Wu H Q 2001 Solid State Ionics 143173

Zaghiba K, Brochua F, Guerfia A and Kinoshita K 2001 J. Power Sources 103140

Zhang H L, Liu S H, Li F, Bai S, Liu C, Tan J and Cheng H M 2006 Carbon 442212

Zhang S S, Ding M S, Xu K, Allen J and Jow T R 2001 Electrochem. Solid S. 4 A206 